
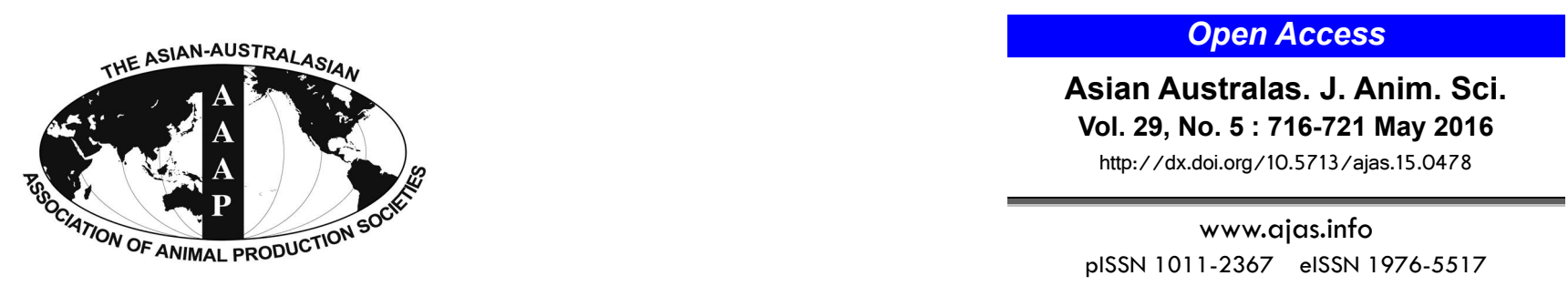

\title{
Effect of Bacillus subtilis Natto on Meat Quality and Skatole Content in TOPIGS Pigs
}

\author{
Q. K. Sheng ${ }^{1,2, *}$, K. F. Zhou ${ }^{3}$, H. M. Hu ${ }^{1}$, H. B. Zhao ${ }^{1}$, Y. Zhang ${ }^{1}$, and W. Ying ${ }^{1}$ \\ ${ }^{1}$ Institute of Animal Science and Veterinary Medicine, Shandong Academy of Agricultural Sciences, \\ Jinan 250100, China
}

\begin{abstract}
This study investigated the effect of Bacillus subtilis (B. subtilis) natto on meat quality and skatole in TOPIGS pigs. Sixty TOPIGS pigs were randomly assigned to 3 groups (including 5 pens per group, with 4 pigs in each pen) and fed with basic diet (control group), basic diet plus $0.1 \%$ B. subtilis natto (B group), and basic diet plus $0.1 \%$ B. subtilis natto plus $0.1 \%$ B. coagulans (BB group), respectively. All pigs were sacrificed at $100 \mathrm{~kg}$. Growth performance, meat quality, serum parameters and oxidation status in the three groups were assessed and compared. Most parameters regarding growth performance and meat quality were not significantly different among the three groups. However, compared with the control group, meat $\mathrm{pH}_{24}$, fat and feces skatole and the content of Escherichia coli (E. Coli), Clostridium, $\mathrm{NH}_{3}-\mathrm{N}$ were significantly reduced in the $\mathrm{B}$ and $\mathrm{BB}$ groups, while serum total cholesterol, high density lipoprotein, the levels of liver P450, CYP2A6, and CYP2E1, total antioxidant capability (T-AOC) and glutathione peroxidase and Lactobacilli in feces were significantly increased in the B and BB groups. Further, the combined supplementation of $B$. subtilis natto and $B$. coagulans showed more significant effects on the parameters above compared with $B$. subtilis, and Clostridium, and $\mathrm{NH}_{3}-\mathrm{N}$. Our results indicate that the supplementation of pig feed with $B$. subtilis natto significantly improves meat quality and flavor, while its combination with B. coagulans enhanced these effects. (Key Words: Bacillus subtilis Natto, Bacillus coagulans, Meat Quality, Skatole, TOPIGS Pig)
\end{abstract}

\section{INTRODUCTION}

Customers tend to prefer high quality of meat. Meat quality is mostly determined by appearance, tenderness, flavor, fat content, water-holding capacity, oxidative stability and uniformity (Rosenvold and Andersen, 2003; Lomiwes et al., 2014). Due to different food culture and cooking habits, customers worldwide mostly focus on meat flavor that is affected by meat composition and odors (Zahn et al., 1997). These odors are produced as a result of anaerobic degradation of materials present in feces (Zahn et al., 1997). Skatole (3-methylindole) is one of the most

\footnotetext{
* Corresponding Author: Q. K. Sheng. Tel: +86-531-88622516, Fax:+86-531-88622516, E-mail: shengqingkai71@163.com

${ }^{2}$ Shandong Provincial Key Laboratory of Animal Disease Control and Breeding, Jinan 250100, China.

${ }^{3}$ Shandong Chief Animal Husbandry and Veterinarian Station, Jinan 250002, China.

Submitted Jun. 2, 2015; Revised Aug. 19, 2015; Accepted Sept. 29, 2015
}

malodorous compounds identified in swine feces and is also an off-flavor component of pig meat (Strathe et al., 2013).

Bacillus subtilis (B. subtilis) natto is usually used to produce salt-free fermented soy food. It has been demonstrated that $B$. subtilis natto is activated to strengthen beneficial intestinal flora, inhibit harmful intestinal bacteria, produce protein and starch degradation enzymes, and increase the production of B-complex vitamins (Nagai, 2012; Bhat et al., 2013). B. subtilis natto has been widely used as a probiotic in animal feeds (Giang et al., 2011). It has been demonstrated that the addition of $B$. subtilis improved growth performance, nutrient digestibility and meat quality, and upregulated lipid metabolism in subcutaneous fat of growing-finishing pigs (Meng et al., 2010; Cui et al., 2013), but the relationship between $B$. subtilis and skatole is unclear.

Further, Sheng et al. (2015) reported that B. subtilis natto reduced the content of skatole in pig feces and increased the content of Streptococcus alactolyticus and 
Lactobacillus amylovorus (L. amylovorus) in fermented broths. S. alactolyticus and L. amylovorus are lactic acid bacteria in the intestine (Rinkinen et al. 2004; Eom et al., 2009). Supplementing lactic acid bacteria in the feed has the potential to reduce skatole and improve meat quality (Wajda et al., 2010). B. coagulans is a probiotic known as "sporeforming lactic acid bacteria" and shows resistance to gastric acid and high temperature during feed granulation. $B$. coagulans has been found to stimulate productive performance and improve meat quality in chickens (Zhou et al., 2010). Previous studies mostly examined the efficacy of single probiotic in animal feed on growth performance and meat quality (Zhou et al., 2010; Giang et al., 2011; Nagai, 2012; Bhat et al., 2013). The combined efficacy of two or multiple probiotics, such as $B$. subtilis natto and $B$. coagulans, in improving animal growth performance and meat quality has been rarely studied.

The intramuscular fat has been considered as one of the important factors for meat marbling, tenderness, flavor and water-holding capacity (Faucitano et al., 2004). TOPIGS pigs are characterized by fast growth, low fat and high lean growth, and therefore, are good models for studying meat quality. In the present study, we investigated the role of $B$. subtilis natto and combined probiotics (B. subtilis natto and $B$. coagulans) in improving meat quality and reducing skatole in TOPIGS pigs.

\section{MATERIALS AND METHODS}

\section{Animals and materials}

Sixty neutered healthy TOPICS growing pigs with similar sex ratio, dates of birth, parity and weight $(30.0 \pm 0.5$ $\mathrm{kg}$ ) were purchased from Jinan Lv'an Food Corp. (Jinan, China). B. subtilis natto and B. coagulans at a concentration of $1 \times 10^{9} \mathrm{cfu} / \mathrm{g}$ were provided by the Institute of Animal Science and Veterinary Medicine, Shandong Academy of Agricultural Sciences (Jinan, China). The recipe of basic diet was referred to as the Feeding Standard of Swine (NY/T65-2004) and produced by Jinan Lv'an Food Corp. It was mostly composed of corn and soybean meal (Table 1). All animal procedures were approved by the ethics committee of Shandong Academy of Agricultural Sciences.

All pigs were randomly assigned to three groups, with each group comprising 5 individual pen replicates including 4 pigs per pen, and fed with basic diet (control group), basic diet plus $0.1 \%$ B. subtilis natto (B group), and basic diet plus $0.1 \%$ B. subtilis natto plus $0.1 \%$ B. coagulans (BB group), respectively. All pigs were housed in an environmentally controlled room at a temperature of $25^{\circ} \mathrm{C}$ and $60 \%$ humidity and managed by a designated person. All pigs were allowed access to feed and water ad libitum throughout the experimental period. The body weight (BW) before and after the experiment were measured to calculate
Table 1. Nutritional composition of the basal diet

\begin{tabular}{lcc}
\hline \multirow{2}{*}{ Items } & \multicolumn{2}{c}{ Growth phase } \\
\cline { 2 - 3 } & 30 to $60 \mathrm{~kg}$ & 60 to $100 \mathrm{~kg}$ \\
\hline Ingredients & 68.2 & 70.8 \\
Corn (\%) & 21 & 16.0 \\
Soybean meal (\%) & 8 & 10.5 \\
Wheat bran (\%) & 0.3 & 0.3 \\
Salt (\%) & 0.1 & 0.1 \\
L-lysine hydrochloride (\%) & 0.9 & 0.9 \\
Calcium carbonate (\%) & 0.5 & 0.4 \\
Calcium hydrophosphate (\%) & 1.0 & 1.0 \\
Vitamin-mineral premix ${ }^{1}(\%)$ & 100 & 100 \\
Total & & \\
Nutrient levels & 12.88 & 12.88 \\
Metabolizable energy (MJ/kg) & 16.0 & 14.6 \\
Crude protein (\%) & 0.58 & 0.49 \\
Calcium (\%) & 0.53 & 0.46 \\
Total Phosphorous (\%) & 0.79 & 0.71 \\
Lysine (\%) & 0.24 & 0.22 \\
Methionine (\%) & 0.55 & 0.49 \\
Threonine (\%) &
\end{tabular}

${ }^{1}$ Mixture contained the following components: $100 \mathrm{mg} / \mathrm{kg}$ iron (as iron sulfate), $30 \mathrm{mg} / \mathrm{kg}$ copper (as copper sulfate), $100 \mathrm{mg} / \mathrm{kg}$ zinc (as zinc sulfate), $20 \mathrm{mg} / \mathrm{kg}$ manganese (as manganese sulfate), $0.03 \mathrm{mg} / \mathrm{kg}$ selenium (as sodium selenite), $0.04 \mathrm{mg} / \mathrm{kg}$ iodine (as potassium iodate), $1,650 \mathrm{IU} / \mathrm{kg}$ vitamin A (trans-retinyl acetate), $280 \mathrm{IU} / \mathrm{kg}$ vitamin $\mathrm{D}_{3}, 22$ $\mathrm{IU} / \mathrm{kg}$ vitamin $\mathrm{E}$ (DL-alpha-tocopherol acetate), $2 \mathrm{mg} / \mathrm{kg}$ vitamin $\mathrm{K}_{3}, 20$ $\mathrm{mg} / \mathrm{kg}$ niacin, $15 \mathrm{mg} / \mathrm{kg}$ pantothenic acid, $1.0 \mathrm{mg} / \mathrm{kg}$ folic acid, 0.03 $\mathrm{mg} / \mathrm{kg}$ vitamin $B_{12}, 2.4 \mathrm{mg} / \mathrm{kg}$ vitamin $B_{1}, 5 \mathrm{mg} / \mathrm{kg}$ vitamin $B_{2}, 2.4 \mathrm{mg} / \mathrm{kg}$ vitamin $\mathrm{B}_{6}$. The carrier was zeolite.

the average daily gain (ADG). The weather, feed intake per pen $(n=5)$ and healthy conditions were recorded every day. The average daily feed intake (ADFI) and feed intake/gain (F/G) were calculated.

\section{Sample collection}

After fasting overnight, $10 \mathrm{~mL}$ of venous blood was collected from the inferior vena cava of all pigs and centrifuged at $1,000 \mathrm{~g}$ for $5 \mathrm{~min}$ to collect serum $(\mathrm{n}=20)$. All pigs were sacrificed at a BW of $\sim 100 \mathrm{~kg}$ at Jinan Lv'an Food Corp. and fragmented according to the conventional procedure $(\mathrm{n}=20)$. The backfat thickness and loin eye area were measured. A 20 to $30 \mathrm{~cm}$ of longissimus from the last third or fourth rib to back was separatly assessed to measure meat color, water-holding capacity, $\mathrm{pH}$ values at 1 and 24 hrs $\left(\mathrm{pH}_{1}\right.$ and $\left.\mathrm{pH}_{24}\right)$, and intramuscular fat content. Twenty grams of back fat and $5 \mathrm{~g}$ of liver tissue were collected and frozen at $-18^{\circ} \mathrm{C}$. The feces from the rectum of two pigs in each pen were collected to analyze skatole and bacterial composition ( $\mathrm{n}=10$ in each group). All sample collection was completed within $30 \mathrm{~min}$.

\section{Measurement of meat, serum, liver and feces parameters}

Backfat thickness and loin eye area were measured 
Table 2. Effect of Bacillus subtilis natto on growth performance

\begin{tabular}{lccccc}
\hline & IBW $(\mathrm{kg} / \mathrm{h})$ & FBW $(\mathrm{kg} / \mathrm{h})$ & ADFI $(\mathrm{kg} / \mathrm{d} \cdot \mathrm{h})$ & ADG $(\mathrm{kg} / \mathrm{d} \cdot \mathrm{h})$ & F/G $(\mathrm{kg} / \mathrm{kg})$ \\
\hline Number & 20 & 20 & 5 & 20 & 5 \\
Control & $30.09 \pm 0.44$ & $101.55 \pm 8.70$ & $2.22 \pm 0.11$ & $0.85 \pm 0.09$ & $2.61 \pm 0.15$ \\
B group $^{1}$ & $30.13 \pm 0.41$ & $103.39 \pm 10.61$ & $2.26 \pm 0.10$ & $0.87 \pm 0.07$ & $2.59 \pm 0.13$ \\
BB group $^{1}$ & $30.04 \pm 0.39$ & $103.62 \pm 11.24$ & $2.27 \pm 0.14$ & $0.88 \pm 0.10$ & $2.59 \pm 0.10$ \\
F-value & 0.10 & 0.54 & 0.35 & 0.26 & 0.08 \\
\hline
\end{tabular}

Bacillus subtilis, B. subtilis; IBW, initial body weight; FBW, final body weight; ADFI, average daily feed intake; ADG, average daily gain; F/G, feed intake/gain.

${ }^{1}$ B group, plus B. subtilis natto group; BB group, plus B. subtilis natto and B. coagulans group.

according to the protocol described by Chen and Wang (1997). The meat parameters including color, water-holding capacity, $\mathrm{pH}_{1}, \mathrm{pH}_{24}$ and intramuscular fat content were measured according to "Determination of pig meat quality technical specifications" (NY/T821-2004). The fatty acids were measured by gas chromatography at Food Detection Center of the Ministry of Agriculture following "Meat and meat products-Determination of fatty acids" specifications (GB9695.2-2008). The levels of serum triglycerides (TG), total cholesterol (TC), high density lipoprotein (HDL), low density lipoprotein (LDL), total antioxidant capability (T$\mathrm{AOC}$ ) and glutathione peroxidase (GSH-PX) were measured by the kits supplied by Nanjing Jiancheng Biotechnology Corp. (Nanjing, China). The serum and liver cytochrome P450 (P450), cytochrome oxidase 2A6 (CYP2A6) and cytochrome oxidase 2E1 (CYP2E1) were measured using the enzyme-linked immunosorbent assay kits from Wuhan Beinglay Biotechnology Corp. (Wuhan, China). The liver tissue parameters were measured using the supernatant obtained by homogenizing and centrifuging $1.0 \mathrm{~g}$ liver tissue in $9.0 \mathrm{~mL}$ cold physiological saline. The skatole levels were measured in the supernatant following homogenization and centrifugation of $2.0 \mathrm{~g}$ fat or feces in $18.0 \mathrm{~mL}$ cold methanol. The skatole level in the supernatant was measured by high-performance liquid chromatography at Food Detection Center of Ministry of Agriculture (Jinan, China). The numbers of Lactobacilli, E. coli, and Clostridium were assessed by plate count, while the $\mathrm{NH}_{3}-\mathrm{N}$ level in feces was measured by Nessler colorimetry.

\section{Statistical analysis}

The SAS 9.2 program (SAS Institute, Cary, NC, USA) was used for statistical analyses. All data were presented as mean \pm standard error of the mean and analyzed by one-way analysis of variance. The Bonferonni correction was used for multiple comparisons. Statistical significance was defined as $\mathrm{p}<0.05$.

\section{RESULTS}

\section{Effect of $B$. subtilis natto on growth performance and meat quality}

There were no significant differences in initial BW and final BW, ADG, ADFI, and F/G among the three groups $(p>0.05$, Table 2).

The meat parameters including backfat thickness, loin eye area, color, water-holding capacity, intramuscular fat content, palmitic acid, stearic acid, oleic acid, and linoleic acid were not significantly different between the three groups ( $>0.05$, Tables 3 and 4). However, compared with

Table 3. Effect of Bacillus subtilis natto on meat parameters

\begin{tabular}{lccccccc}
\hline & $\begin{array}{c}\text { Backfat thickness } \\
(\mathrm{mm})\end{array}$ & $\begin{array}{c}\text { Loin eye area } \\
\left(\mathrm{cm}^{2}\right)\end{array}$ & Color L value & $\begin{array}{c}\text { Water-holding } \\
\text { capacity }(\%)\end{array}$ & $\mathrm{pH}_{1}$ & $\mathrm{pH}_{24}$ & $\begin{array}{c}\text { Fat skatole } \\
(\mu \mathrm{g} / \mathrm{kg})\end{array}$ \\
\hline Control $^{1}$ & $11.30 \pm 0.24$ & $44.87 \pm 1.55$ & $48.18 \pm 2.33$ & $2.79 \pm 1.87$ & $6.20 \pm 0.14$ & $5.47 \pm 0.06^{\mathrm{a}}$ & $14.86 \pm 1.27^{\mathrm{a}}$ \\
B group $^{1}$ & $10.00 \pm 0.21$ & $43.77 \pm 1.74$ & $48.71 \pm 2.57$ & $2.84 \pm 2.21$ & $6.23 \pm 0.13$ & $5.51 \pm 0.04^{\mathrm{b}}$ & $13.61 \pm 2.09^{\mathrm{b}}$ \\
BB group $^{1}$ & $10.77 \pm 0.40$ & $43.60 \pm 2.37$ & $46.99 \pm 3.26$ & $2.88 \pm 1.96$ & $6.29 \pm 0.09$ & $5.55 \pm 0.08^{\mathrm{c}}$ & $12.42 \pm 1.95^{\mathrm{c}}$ \\
F-value $^{2}$ & 2.78 & 1.34 & 1.88 & 1.29 & 2.50 & 8.77 & 14.28 \\
\hline
\end{tabular}

${ }^{1}$ B group, plus B. subtilis natto group; BB group, plus B. subtilis natto and B. coagulans group.

${ }^{\mathrm{a}, \mathrm{b}, \mathrm{c}}$ Means within same column with different superscript letters are significantly different $(\mathrm{p}<0.05) . \mathrm{n}=20$.

Table 4. Effect of Bacillus subtilis natto on fatty acids (\%) in the longissimus

\begin{tabular}{lccccc}
\hline & Intramuscular fat & Palmitic acid & Stearic acid & Oleic acid & Linoleic acid \\
\hline Control & $1.56 \pm 0.57$ & $23.62 \pm 1.06$ & $12.27 \pm 0.96$ & $42.87 \pm 4.34$ & $8.83 \pm 1.67$ \\
B group $^{1}$ & $1.85 \pm 0.49$ & $24.23 \pm 0.94$ & $12.33 \pm 0.68$ & $45.70 \pm 1.48$ & $6.28 \pm 1.41$ \\
BB group $^{1}$ & $1.62 \pm 0.44$ & $24.58 \pm 0.70$ & $12.25 \pm 0.65$ & $45.23 \pm 2.10$ & $6.23 \pm 1.39$ \\
F-value & 0.59 & 1.48 & 0.12 & 1.63 & 2.41 \\
\hline
\end{tabular}

$\mathrm{n}=20$.

${ }^{1}$ B group, plus B. subtilis natto group; BB group, plus B. subtilis natto and B.coagulans group. 
the control group, $\mathrm{pH}_{24}$ in meat was significantly increased while the level of fat skatole was significantly reduced in the B and BB groups $(p<0.05$, Table 3$)$. There were no significant differences in $\mathrm{pH}_{24}$ and fat skatole between $\mathrm{B}$ and BB groups ( $>>0.05$, Table 3$)$.

\section{Effect of $B$. subtilis natto on serum parameters}

Compared with the control group, the levels of TG and LDL were not changed $(\mathrm{p}>0.05)$ while the TC and HDL levels were significantly reduced in the B and BB groups $(p<0.05$, Table 5). Further, the levels of TC and HDL in the BB group were significantly lower than in the B group $(\mathrm{p}<0.05$, Table 5).

Effect of $B$. subtilis natto on the oxidative parameters of serum and liver

To examine the effects of $B$. subtilis natto and $B$. coagulans on oxidative status in pigs, we first assessed the levels of serum T-AOC, GSH-PX, P450, CYP2A6, and CYP2E1 and observed that the levels of serum T-AOC and GSH-PX were significantly increased in the $\mathrm{B}$ and $\mathrm{BB}$ groups compared with the control group $(\mathrm{p}<0.05$ or $\mathrm{p}<0.01$, Table 5). Further, serum T-AOC in the BB group was significantly higher than in the B group $(\mathrm{p}<0.05$, Table 6$)$. The serum P450, CYP2A6, and CYP2E1 levels were very low and not significantly different among the three groups ( $>0.05$, Table 6).

We also examined the levels of P450, CYP2A6, and CYP2E1 in the liver and found that the levels of P450, CYP2A6, and CYP2E1 in the B and BB groups were significantly higher than those in the control group $(\mathrm{p}<0.05$, Table 6). However, there were no significant differences in
Table 5. Effect of Bacillus subtilis natto on serum parameters $(\mathrm{mmol} / \mathrm{L})$

\begin{tabular}{lcccc}
\hline & TC & TG & HDL & LDL \\
\hline Control $^{1}$ & $2.33 \pm 0.57^{\mathrm{a}}$ & $0.27 \pm 0.13$ & $1.64 \pm 0.53^{\mathrm{a}}$ & $0.48 \pm 0.39$ \\
B group $^{1}$ & $2.21 \pm 0.87^{\mathrm{b}}$ & $0.23 \pm 0.09$ & $1.34 \pm 0.33^{\mathrm{b}}$ & $0.45 \pm 0.47$ \\
BB group $^{1}$ & $2.07 \pm 0.55^{\mathrm{c}}$ & $0.22 \pm 0.09$ & $1.06 \pm 0.37^{\mathrm{c}}$ & $0.42 \pm 0.36$ \\
F-value & 6.56 & 1.59 & 6.01 & 0.81 \\
\hline
\end{tabular}

TC, total cholesterol; TG, triglyceride; HDL, high density lipoprotein; LDL, low density lipoprotein.

${ }^{1}$ B group, plus B. subtilis natto group; BB group, plus B. subtilis natto and B.coagulans group.

a,b,c Means within same column with different superscript letters are significantly different $(\mathrm{p}<0.05) . \mathrm{n}=20$.

the levels of hepatic P450, CYP2A6, and CYP2E1 between $\mathrm{B}$ and $\mathrm{BB}$ groups ( $>0.05$, Table 6$)$.

\section{Effect of $B$. subtilis natto on skatole production and bacterial composition in the feces}

Compared with the control group, the Lactobacilli in the feces were increased while the numbers of $E$. coli and Clostridium and the levels of $\mathrm{NH}_{3}-\mathrm{N}$ and skatole in feces were significantly decreased in the $\mathrm{B}$ and $\mathrm{BB}$ groups $(\mathrm{p}<0.05$, Table 7). There were significant differences in the numbers of Lactobacillus, and Clostridium, and the levels of $\mathrm{NH}_{3}-\mathrm{N}$ in feces between $\mathrm{B}$ and BB group except $E$. coli and skatole $(\mathrm{p}<0.05$, Table 7$)$.

\section{DISCUSSION}

Meat quality is affected by many different factors, such as intramuscular fat, skatole level in meat, etc. However, the production of skatole is associated with the intestinal

Table 6. Effects of Bacillus subtilis natto on serum and liver oxidative parameters

\begin{tabular}{|c|c|c|c|c|c|c|c|c|}
\hline & \multicolumn{5}{|c|}{ Serum } & \multicolumn{3}{|c|}{ Liver } \\
\hline & $\begin{array}{c}\text { T-AOC } \\
\text { (U/L) }\end{array}$ & $\begin{array}{c}\text { GSH-PX } \\
(\mathrm{U} / \mathrm{mL})\end{array}$ & $\begin{array}{c}\mathrm{P} 450 \\
(\mathrm{ng} / \mathrm{mL})\end{array}$ & $\begin{array}{l}\text { CYP2A6 } \\
\text { (ng/mL) }\end{array}$ & $\begin{array}{l}\text { CYP2E1 } \\
\text { (ng/mL) }\end{array}$ & $\begin{array}{c}\mathrm{P} 450 \\
(\mathrm{ng} / \mathrm{mL})\end{array}$ & $\begin{array}{l}\text { CYP2A6 } \\
\text { (ng/g) }\end{array}$ & $\begin{array}{l}\text { CYP2E1 } \\
\text { (ng/g) }\end{array}$ \\
\hline Control & $4.37 \pm 0.21^{\mathrm{c}}$ & $366.59 \pm 15.48^{b}$ & $0.22 \pm 0.04$ & $0.12 \pm 0.01$ & $0.16 \pm 0.02$ & $1.85 \pm 0.13^{b}$ & $1.02 \pm 0.09^{b}$ & $1 . .32 \pm 0.14^{\mathrm{b}}$ \\
\hline B group ${ }^{1}$ & $5.88 \pm 0.55^{\mathrm{b}}$ & $382.31 \pm 9.77^{\mathrm{a}}$ & $0.26 \pm 0.05$ & $0.14 \pm 0.02$ & $0.17 \pm 0.04$ & $2.07 \pm 0.17^{\mathrm{a}}$ & $1.15 \pm 0.11^{\mathrm{a}}$ & $1.49 \pm 0.19^{\mathrm{a}}$ \\
\hline $\mathrm{BB}_{\text {group }^{1}}$ & $8.10 \pm 0.45^{\mathrm{a}}$ & $382.44 \pm 12.02^{\mathrm{a}}$ & $0.26 \pm 0.04$ & $0.14 \pm 0.03$ & $0.17 \pm 0.03$ & $2.09 \pm 0.19^{\mathrm{a}}$ & $1.18 \pm 0.18^{\mathrm{a}}$ & $1.51 \pm 0.21^{\mathrm{a}}$ \\
\hline F-value & 9.77 & 2.89 & 1.08 & 1.24 & 0.88 & 4.31 & 5.07 & 5.78 \\
\hline
\end{tabular}

T-AOC, total antioxidant capability; GSH-PX, glutathione peroxidase; P450, cytochrome P450; CYP2A6, cytochrome oxidase 2A6; CYP2E1, cytochrome oxidase $2 \mathrm{E} 1$.

${ }^{1}$ B group, plus B. subtilis natto group; BB group, plus B. subtilis natto and B.coagulans group.

${ }^{a, b, c}$ Means within same column with different superscript letters are significantly different $(\mathrm{p}<0.05) . \mathrm{n}=20$.

Table 7. Effect of Bacillus subtilis natto on skatole production and fecal bacterial composition

\begin{tabular}{lccccc}
\hline & $\begin{array}{c}\text { Lactobacillus } \\
(\log 10 \mathrm{CFU} / \mathrm{g})\end{array}$ & $\begin{array}{c}\text { Escherichia coli } \\
(\log 10 \mathrm{CFU} / \mathrm{g})\end{array}$ & $\begin{array}{c}\text { Clostridium } \\
(\log 10 \mathrm{CFU} / \mathrm{g})\end{array}$ & $\begin{array}{c}\mathrm{NH}_{3}-\mathrm{N} \\
(\mathrm{g} / \mathrm{kg})\end{array}$ & $\begin{array}{c}\text { Skatole } \\
(\mathrm{mg} / \mathrm{kg})\end{array}$ \\
\hline Control $^{1}$ & $5.74 \pm 0.12^{\mathrm{c}}$ & $5.38 \pm 0.11^{\mathrm{a}}$ & $5.55 \pm 0.09^{\mathrm{a}}$ & $1.64 \pm 0.16^{\mathrm{a}}$ & $23.66 \pm 3.33^{\mathrm{a}}$ \\
B group $^{1}$ & $7.06 \pm 0.09^{\mathrm{b}}$ & $5.14 \pm 0.14^{\mathrm{b}}$ & $4.92 \pm 0.08^{\mathrm{b}}$ & $0.71 \pm 0.18^{\mathrm{b}}$ & $18.39 \pm 2.19^{\mathrm{b}}$ \\
BB group $^{1}$ & $7.44 \pm 0.11^{\mathrm{a}}$ & $5.02 \pm 0.13^{\mathrm{b}}$ & $4.76 \pm 0.08^{\mathrm{c}}$ & $0.55 \pm 0.12^{\mathrm{c}}$ & $17.21 \pm 2.09^{\mathrm{b}}$ \\
F-value & 52.84 & 18.98 & 49.31 & 29.77 & 6.45 \\
\hline
\end{tabular}

${ }^{1}$ B group, plus B. subtilis natto group; BB group, plus B. subtilis natto and B.coagulans group.

${ }^{\mathrm{a}, \mathrm{b}, \mathrm{c}}$ Means within same column with different superscript letters are significantly different $(\mathrm{p}<0.05) . \mathrm{n}=10$. 
bacterial composition and the enzymes secreted by the intestine. Thus, intestinal bacterial composition is one of the key factors that affect meat quality. In the present study, we observed that supplementation of $B$. subtilis natto in pig feed significantly changed the bacterial composition, increased CYP2E1 level in the liver and decreased skatole content in the fat and feces. These data indicate that $B$. subtilis natto supplementation of pig feed significantly improved meat quality.

Skatole is a malodorous chemical in pig meat and manure and is as an off-flavor component (referred to as "boar taint") (Strathe et al., 2013). Further, skatole has been found to pollute the environment and cause acute bovine pulmonary edema and emphysema (Linden et al., 1996). In this study, we demonstrated that pig feed supplementation using $B$. subtilis natto significantly decreased the skatole content of the fat and feces. This result is supported by two major findings. First, compared with the control group, reduced number of Clostridium in the feces was consistent with lower skatole content in the fat and feces in the B and BB groups. It has been demonstrated that Clostridium in the feces is involved in the transformation of tryptophan to skatole (Whitehead et al., 2008; Doerner et al., 2009). Second, we observed increased levels of CYP2A and CYP2E1 in the liver from B and BB groups, indicating increased metabolism of skatole in the $\mathrm{B}$ and $\mathrm{BB}$ groups. CYP2A and CYP2E1 in the liver are two important proteinases for the degradation of skatole (Zamaratskaia et al., 2006; Wiercinska et al., 2012). However, the mechanisms underlying reduction in the number of Clostridium and increased CYP2A6 and CYP2E1 levels in the liver by $B$. subtilis natto and B. coagulans need further investigation. Similar to CYP2A6 and CYP2E1, T-AOC and GSH-PX are two major biomarkers of oxidative status in the body. Here we also observed that B. subtilis natto supplementation of pig feed significantly increased serum T-AOC and GSH-PX, but it is unclear whether B. subtilis natto increased the antioxidant function via natto kinase and catalase (Hosoi et al., 2000; Yongjun et al., 2011).

In the present study, we also observed that the supplementation of B. subtilis natto in pig feed significantly decreased serum TC and increased serum HDL although not supported by any evidence. The result may be related to $\mathrm{P} 450$ or natto kinase because $\mathrm{P} 450$ and its family members including CYP8B, CYP4A, and CYP7A1 are involved in the cholesterol metabolism (Norlin and Wikvall, 2007; Lundell and Wikvall, 2008). Further, the combination of natto kinase and red yeast rice decreased the TC level in the patients with high blood lipids (Yang et al., 2009). Interestingly, the $B$. subtilis natto supplementation failed to increase growth performance of pigs, in which the FBW, ADG, F/G backfat thickness, loin eye area, meat color, water-holding capacity and intramuscular fat were very similar among the three groups. These findings are not consistent with previous study in which dietary supplementation of $B$. subtilis increased growth performance throughout the experiment (Meng et al., 2010). The discrepancy between two studies may be caused by different pig species and B. subtilis resources. Additionally, the $B$. subtilis natto supplementation increased meat $\mathrm{pH}_{24}$ value, which is related to anaerobic glycolysis in meat.

More importantly, the combined supplementation of $B$. subtilis natto and $B$. coagulans resulted in similar or better results in improving meat quality and antioxidant capacity and reducing skatole content compared with $B$. subtilis natto alone. These data suggest that $B$. subtilis natto and $B$. coagulans may exert synergistic effects in the pigs.

However, the study limitations are as follows. First, all parameters were measured only at the endpoint. The selection of endpoint at $100 \mathrm{~kg}$ may be a little arbitrary for evaluating growth performance and meat quality because growth performance is decreased and fat deposition is increased at the late stage of pig growth. Therefore, the delayed endpoint may affect the evaluation of growth performance. Second, the effects of B. coagulans in animal feed have been rarely studied, so it will be interesting to set an individual $B$. coagulans group.

In conclusion, $B$. subtilis natto supplementation of pig feed significantly improves meat quality, increases antioxidant function and reduces skatole production. Further, the combined supplementation of $B$. subtilis natto and $B$. coagulans has better effects.

\section{CONFLICT OF INTEREST}

We certify that there is no conflict of interest with any financial organization regarding the material discussed in the manuscript.

\section{ACKNOWLEDGMENTS}

The authors acknowledge Medjaden Bioscience Limited for assistance with manuscript preparation. This project was supported by a grant from the National Natural Science Foundation of China (No. 31172245).

\section{REFERENCES}

Bhat, A. R., V. U. Irorere, T. Bartlett, D. Hill, G. Kedia, M. R. Morris, D. Charalampopoulos, and I. Radecka. 2013. Bacillus subtilis natto: A non-toxic source of poly-gamma-glutamic acid that could be used as a cryoprotectant for probiotic bacteria. AMB Express 3:36.

Chen, Q. M. and L. C. Wang. 1997. Modern pig production. China Agricultural University Press, Beijing, China. 68-69:353-357.

Cui, C., C. J. Shen, G. Jia, and K. N. Wang. 2013. Effect of dietary Bacillus subtilis on proportion of Bacteroidetes and Firmicutes 
in swine intestine and lipid metabolism. Genet. Mol. Res. 12: 1766-1776.

Doerner, K. C., K. L. Cook, and B. P. Mason. 2009. 3Methylindole production is regulated in Clostridium scatologenes ATCC 25775. Lett. Appl. Microbiol. 48:125-132.

Eom, H. J., J. S. Moon, E. Y. Seo, and N. S. Han. 2009. Heterologous expression and secretion of Lactobacillus amylovorus alpha-amylase in Leuconostoc citreum. Biotechnol. Lett. 31:1783-1788.

Faucitano, L., J. Rivest, J. P. Daigle, J. Levesque, and C. Gariepy. 2004. Distribution of intramuscular fat content and marbling within the longissimus muscle of pigs. Can. J. Anim. Sci. 84:57-61.

Giang, H. H., T. Q. Viet, B. Ogle, and J. E. Lindberg. 2011. Effects of supplementation of probiotics on the performance, nutrient digestibility and faecal microflora in growing-finishing pigs. Asian Australas. J. Anim. Sci. 24:655-661.

Hosoi, T., A. Ametani, K. Kiuchi, and S. Kaminogawa. 2000. Improved growth and viability of lactobacilli in the presence of Bacillus subtilis (natto), catalase, or subtilisin. Can. J. Microbiol. 46:892-897.

Linden, A., D. Desmecht, S. Vandenput, M. L. Van De Weerdt, and P. Lekeux. 1996. Effect of serotonergic blockade on calf pulmonary function after the intravenous administration of 3methylindole. J. Comp. Pathol. 114:361-371.

Lomiwes, D., M. M. Farouk, E. Wiklund, and O. A. Young. 2014. Small heat shock proteins and their role in meat tenderness: A review. Meat Sci. 96:26-40.

Lundell, K. and K. Wikvall. 2008. Species-specific and agedependent bile acid composition: Aspects on CYP8B and CYP4A subfamilies in bile acid biosynthesis. Curr. Drug Metab. 9:323-331.

Meng, Q. W., L. Yan, X. Ao, T. X. Zhou, J. P. Wang, J. H. Lee, and I. H. Kim. 2010. Influence of probiotics in different energy and nutrient density diets on growth performance, nutrient digestibility, meat quality, and blood characteristics in growing-finishing pigs. J. Anim. Sci. 88:3320-3326.

Nagai, T. 2012. Bacteriophages of Bacillus subtilis (natto) and their contamination in natto factories. Bacteriophages (Ed. I. Kurtboke). InTech, Rijeka, Croatia. pp 95-110.

Norlin, M. and K. Wikvall. 2007. Enzymes in the conversion of cholesterol into bile acids. Curr. Mol. Med. 7:199-218.

Rinkinen, M. L., J. M. Koort, A. C. Ouwehand, E. Westermarck, and K. J. Björkroth. 2004. Streptococcus alactolyticus is the dominating culturable lactic acid bacterium species in canine jejunum and feces of four fistulated dogs. FEMS Microbiol. Lett. 230:35-39.
Rosenvold, K. and H. J. Andersen. 2003. Factors of significance for pork quality-A review. Meat Sci. 64:219-237.

Sheng, Q. K., Z. J. Yang, H. B. Zhao, X. L. Wang, and J. F. Guo. 2015. Effects of L-tryptophan, fructan, and casein on reducing ammonia, hydrogen sulfide, and skatole in fermented swine manure. Asian Australas. J. Anim. Sci. 28:1202-1208.

Strathe, A. B., I. H. Velander, T. Mark, and H. N. Kadarmideen. 2013. Genetic parameters for androstenone and skatole as indicators of boar taint and their relationship to production and litter size traits in Danish Landrace. J. Anim. Sci. 91:25872595.

Wajda, S., K. Smiecińska, J. Jankowski, P. Matusevicius, and G. Buteikis. 2010. The efficacy of lactic acid bacteria Pediococcus acidilactici, lactose and formic acid as dietary supplements for turkeys. Pol. J. Vet. Sci. 13:45-51.

Whitehead, T. R., N. P. Price, H. L. Drake, and M. A. Cotta. 2008. Catabolic pathway for the production of skatole and indoleacetic acid by the acetogen Clostridium drakei, Clostridium scatologenes, and swine manure. Appl. Environ. Microbiol. 74:1950-1953.

Wiercinska, P., Y. Lou, and E. J. Squires. 2012. The roles of different porcine cytochrome P450 enzymes and cytochrome b5A in skatole metabolism. Animal 6:834-845.

Yang, N. C., C. W. Chou, C. Y. Chen, K. L. Hwang, and Y. C. Yang. 2009. Combined nattokinase with red yeast rice but not nattokinase alone has potent effects on blood lipids in human subjects with hyperlipidemia. Asia. Pac. J. Clin. Nutr. 18:310317.

Yongjun, C., B. Wei, J. Shujun, W. Meizhi, J. Yan, Y. Yan, Z. Zhongliang, and Z. Goulin. 2011. Directed evolution improves the fibrinolytic activity of nattokinase from Bacillus natto. FEMS Microbiol. Lett. 325:155-161.

Zahn, J. A., J. L. Hatfield, Y. S. Do, A. A. Dispirito, D. A. Laird, and R. L. Pfeiffer. 1997. Characterization of volatile organic emissions and wastes from swine production facilities. J. Environ. Qual. 26:1687-1696.

Zamaratskaia, G., G. Chen, and K. Lundstrom. 2006. Effects of sex, weight, diet and hCG administration on levels of skatole and indole in the liver and hepatic activities of cytochromes P4502E1 and P4502A6 in pigs. Meat Sci. 72:331-338.

Zhou, X., Y. Wang, Q. Gu, and W. Li. 2010. Effect of dietary probiotic, Bacillus coagulans, on growth performance, chemical composition, and meat quality of Guangxi Yellow chicken. Poult. Sci. 89:588-593. 